\title{
Manejo de nitrogênio no milho sob plantio direto com diferentes plantas de cobertura, em Latossolo Vermelho
}

\author{
Edson Cabral da Silva( ${ }^{(1)}$, Takashi Muraoka(1), Salatiér Buzetti(2) e Paulo César Ocheuze Trivelin ${ }^{(1)}$
}

\begin{abstract}
(1)Universidade de São Paulo, Centro de Energia Nuclear na Agricultura, Av. Centenário, № 303, CEP 13416-000 Piracicaba, SP. E-mail: ecsilva@cena.usp.br, muraoka@cena.usp.br, pcotrive@cena.usp.br (2)Universidade Estadual Paulista Júlio de Mesquita Filho, Av. Brasil, no 56, CEP 15385-000 Ilha Solteira, SP. E-mail: sbuzetti@agr.feis.unesp.br
\end{abstract}

\begin{abstract}
Resumo - O objetivo deste trabalho foi definir a melhor dose e época de aplicação, e a eficiência de utilização do $\mathrm{N}$, utilizando-se uréia marcada com ${ }^{15} \mathrm{~N}$, pelo milho cultivado sob plantio direto, em sucessão à crotalária (Crotalaria juncea), ao milheto (Pennisetum americanum) e à vegetação espontânea (pousio), em um Latossolo Vermelho no Cerrado. O delineamento experimental foi o de blocos ao acaso, com 24 tratamentos e quatro repetições, em esquema fatorial incompleto, 3x3x2 + 6: três doses de N (80, 130 e 180 kg ha-1); três sistemas de cobertura do solo (crotalária, milheto e pousio); duas épocas de aplicação do N (estádio quatro ou oito folhas); e seis tratamentos adicionais (três sem aplicação de $\mathrm{N}$ e três que receberam $30 \mathrm{~kg} \mathrm{ha}^{-1}$ de $\mathrm{N}$ na semeadura). O cultivo do milho em sucessão à crotalária proporciona maior quantidade na planta e aproveitamento pela planta do $\mathrm{N}$ proveniente do fertilizante e maior produtividade de grãos. A aplicação do $\mathrm{N}$ ao milho com quatro folhas proporciona maior produtividade de grãos, comparada à aplicação com oito folhas, quando em sucessão ao milheto.
\end{abstract}

Termos para indexação: Zea mays, fertilizante ${ }^{15} \mathrm{~N}$, pousio, adubo verde, Cerrado, plantio direto.

\section{Nitrogen management in corn under no-tillage with different cover crops in a Rhodic Hapludox soil}

\begin{abstract}
The objective of this work was to evaluate the best rate and time for $\mathrm{N}$ application, and $\mathrm{N}$ utilization using urea- ${ }^{15} \mathrm{~N}$, by corn crop grown under no-tillage system, in succession to sun hemp (Crotalaria juncea L.), millet (Pennisetum americanum) and to the spontaneous vegetation (fallow ground), in a Rhodic Hapludox soil in Cerrrado. The experimental design was randomized complete blocks, with 24 treatments and four replications, in an incomplete factorial 3x3x2 +6: three $\mathrm{N}$ rates $\left(80,130\right.$ and $\left.180 \mathrm{~kg} \mathrm{ha}^{-1} \mathrm{~N}\right)$; three preceding cover crops (sun hemp, millet and fallow ground); two $\mathrm{N}$ application time (four leaves or eight leaves stage); and six additional treatments (three without $\mathrm{N}$ application and three that received $30 \mathrm{~kg} \mathrm{ha}^{-1} \mathrm{~N}$ at seeding). The corn grown in succession to sun hemp provided higher amount of $\mathrm{N}$ derived from fertilizer, $\mathrm{N}$ utilization efficiency and grain yield. Application of $\mathrm{N}$ to corn four leaves stage provides higher grain yield, compared to the application to eight leaves stage, in succession to millet.
\end{abstract}

Index terms: Zea mays, fertilizer ${ }^{15} \mathrm{~N}$, fallow, green manure, Cerrado, no-tillage.

\section{Introdução}

O milho é o principal cereal produzido no Brasil, cultivado em cerca de 13 milhões de hectares, com produção de aproximadamente 42 milhões de toneladas de grãos e produtividade média de 3,2 toneladas por hectare (Conab, 2005). Entre os vários fatores que causam essa baixa produtividade, destacam-se o baixo consumo e o manejo incorreto do $\mathrm{N}$, nutriente absorvido em maior quantidade pelo milho, que mais influencia na resposta em produtividade de grãos e mais onera no custo de produção da cultura (Amado et al., 2002).
A dinâmica do N no sistema solo-planta, com a conseqüente eficiência da utilização de N pela planta, é influenciada principalmente pelo sistema de cultivo, tipo de fertilizante, formas de manejo e condições edafoclimáticas (Amado et al., 2002; Figueiredo et al., 2005). A maioria dos trabalhos demonstra que existe grande variação no aproveitamento do $\mathrm{N}$ do fertilizante pelo milho, que raramente ultrapassa a $50 \%$ do $\mathrm{N}$ aplicado (Scivittaro et al., 2000). Em estudos que utilizaram a metodologia do ${ }^{15} \mathrm{~N}$, com milho cultivado em sistema plantio direto (SPD), foram encontrados diferentes valores de eficiência de recuperação do $\mathrm{N}$ do 
fertilizante: 10\% (Timmons \& Cruse, 1990), 42\% (Timmons \& Baker, 1992) e 30\% (Lara Cabezas et al., 2000).

De maneira geral, nos estudos citados, aproximadamente $65 \%$ do $\mathrm{N}$ encontrava-se nos grãos e $35 \%$, nas demais partes da planta.

O não-revolvimento do solo promove modificações na ciclagem dos nutrientes, e o $\mathrm{N}$ é o mais afetado, pois com a decomposição mais lenta dos resíduos vegetais deixados na superfície do solo, processos como a imobilização, mineralização, lixiviação, volatilização e desnitrificação são alterados (Lara Cabezas et al., 2000).

Resultados de pesquisas em condições edafoclimáticas diferentes e que apresentam considerável acúmulo de palha, maior teor de matéria orgânica do solo e maior tempo de adoção do SPD, têm influenciado na recomendação de manejo da adubação nitrogenada no milho, para as condições de cerrado. Isto implica a necessidade de mais estudos, para o entendimento da dinâmica e recuperação do N no sistema solo-planta, e possibilita a tomada de decisão quanto a formas de manejo, para que a disponibilidade de $\mathrm{N}$ ocorra em sincronia com a necessidade da cultura (Lara Cabezas et al., 2004; Figueiredo et al., 2005).

A época de aplicação do fertilizante nitrogenado tem grande influência no aproveitamento deste nutriente pelo milho (Mengel \& Barber, 1974). No entanto, não tem havido muita concordância sobre qual a melhor época de aplicação de N no SPD. Alguns resultados de pesquisa têm demonstrado vantagens na aplicação de $\mathrm{N}$ em pré-semeadura do milho (Sá, 1996). Outros demonstram a necessidade de aumento da dose de $\mathrm{N}$, no momento da semeadura, para suprir a carência inicial em função da imobilização, e que parte seja fornecido em cobertura (Bortolini et al., 2002). Contudo, existe uma série de variáveis que condicionam as transformações do $\mathrm{N}$ no solo, que são mediadas por microrganismos, e dependem das condições edafoclimáticas, principalmente do tipo de solo, da precipitação pluvial e da temperatura (Lara Cabezas et al., 2004); dependem, além disso, das características dos resíduos vegetais da cultura de cobertura antecessora ao milho (Amado et al., 2002).

O cultivo de plantas de cobertura do solo na entressafra, em SPD, principalmente de leguminosas, tem demonstrado ser uma alternativa promissora na suplementação de $\mathrm{N}$ para o milho (Gonçalves et al., 2000). A qualidade do resíduo vegetal, sobretudo sua relação $\mathrm{C} / \mathrm{N}$, e a disponibilidade de $\mathrm{N}$ mineral na solução do solo influenciam diretamente a taxa de decomposição (Amado et al., 2002). A elevada capacidade de absorção de $\mathrm{N}$ das gramíneas, em função do seu sistema radicular abundante, constitui-se numa importante estratégia para a reciclagem desse nutriente, durante a entressafra, e para redução dos riscos de contaminação do lençol freático por nitrato (Sá, 1996; Amado et al., 2002). Além disso, resíduos de gramíneas, em virtude de sua baixa taxa de decomposição, proporcionam melhor cobertura do solo (Perin et al., 2004).

Aita et al. (2001), ao avaliar o uso de gramínea, leguminosa e pousio no inverno, evidenciaram a possibilidade de redução das quantidades de $\mathrm{N}$ mineral aplicada ao milho, quando cultivado depois das leguminosas. De-Polli \& Chada (1989), ao estudar a adubação verde incorporada ou em cobertura, na produção de milho em solo de baixo potencial de produtividade, verificaram que essa adubação proporcionou rendimento de grãos maior do que a de $\mathrm{N}$ mineral, e foi até quatro vezes superior à do tratamento controle. Nesse contexto, estabeleceu-se a hipótese de que o uso combinado de uma fonte inorgânica de N, com adubos verdes, poderia aumentar a eficiência de utilização de $\mathrm{N}$ do fertilizante pelo milho cultivado em SPD.

O objetivo deste trabalho foi definir a melhor dose e época de aplicação, e a eficiência de utilização do $\mathrm{N}$, utilizando-se a uréia marcada com ${ }^{15} \mathrm{~N}$, pelo milho cultivado sob plantio direto, em sucessão à crotalária (Crotalaria juncea), ao milheto (Pennisetum americanum) e à vegetação espontânea (pousio), em um Latossolo Vermelho no Cerrado.

\section{Material e Métodos}

O experimento foi conduzido em condições de campo, em área da Fac. de Engenharia de Ilha Solteira Unesp, localizada no município de Selvíria, MS, cujas coordenadas geográficas são $51^{\circ} 22^{\prime} \mathrm{W}$ e $20^{\circ} 22^{\prime} \mathrm{S}, 335 \mathrm{~m}$ de altitude. Segundo a classificação de Köppen, o clima da região é do tipo Aw, definido como tropical úmido, com estação chuvosa no verão e seca no inverno, apresentando temperatura média anual de $24,5^{\circ} \mathrm{C}$, precipitação média anual de 1.370 mm e umidade relativa média de $64,8 \%$.

O solo foi classificado como Latossolo Vermelho distrófico (LVd) típico, argiloso (530 $\mathrm{g} \mathrm{kg}^{-1}$ de argila), A moderado, hipodistrófico, álico, caulinítico, férrico, compactado, muito profundo, moderadamente ácido, fase cerrado, relevo suave ondulado (Embrapa, 1999). 
O experimento constou de dois ensaios, conduzidos nos anos agrícolas de 2001/2002 e de 2002/2003, em áreas individuais e anexas, com histórico de 19 anos de plantio convencional com culturas anuais (feijão, milho, soja e arroz), e últimos cinco anos em plantio direto, cultivado com arroz no último ano agrícola (2000/2001).

Antes da instalação dos ensaios, foram realizadas amostragens do solo, nos meses de julho de 2001 e julho de 2002 , nas camadas de $0,0-0,1,0,1-0,2$ e $0,2-0,4 \mathrm{~m}$, para caracterização química (Tabela 1), segundo metodologias descritas por Raij et al. (2001). A média dos resultados das análises químicas do solo, das camadas de $0,0-0,1$ e $0,1-0,2 \mathrm{~m}$, foi utilizada para o cálculo da adubação com potássio, fósforo e zinco, para o milho, para uma expectativa de produtividade de grãos de 10 a 12 t ha $^{-1}$, conforme Raij et al. (1996).

O delineamento experimental foi em blocos ao acaso, com quatro repetições e 24 tratamentos, dispostos em esquema fatorial incompleto, $3 \times 3 \times 2+6$ tratamentos adicionais, sendo três tratamentos controles, sem a aplicação de $\mathrm{N}\left(0 \mathrm{~kg} \mathrm{ha}^{-1}\right.$ de $\mathrm{N}$ no milho sobre crotalária, milheto e pousio), e três tratamentos que receberam somente $30 \mathrm{~kg} \mathrm{ha}^{-1}$ de $\mathrm{N}$ na semeadura (30 kg ha-1 de N no milho sobre crotalária, milheto e pousio). Os demais tratamentos constituíram-se pela combinação de três doses de $\mathrm{N}$ no milho: 80, 130 e $180 \mathrm{~kg} \mathrm{ha}^{-1}$, tendo sido aplicados $30 \mathrm{~kg} \mathrm{ha}^{-1}$ de $\mathrm{N}$ na semeadura mais 50, 100 e $150 \mathrm{~kg} \mathrm{ha}^{-1}$ de $\mathrm{N}$ em cobertura; três sistemas de cobertura do solo: crotalária, milheto e pousio; e duas épocas de aplicação de N: estádio quatro folhas ou estádio oito folhas. Cada parcela experimental constou de uma área de 44,8 $\mathrm{m}^{2}$ (7,0x6,4 m), com oito linhas de milho espaçadas de $0,80 \mathrm{~m}$. Como área útil, foram consideradas as quatro linhas centrais, tendo-se desprezado $1 \mathrm{~m}$ em cada extremidade, perfazendo uma área de $16 \mathrm{~m}^{2}$.

As semeaduras da crotalária e do milheto foram realizadas mecanicamente, em 17/9/2001, no primeiro ano agrícola, e em 24/9/2002, no segundo. A crotalária foi semeada na densidade de 30 a 40 sementes por $\mathrm{m}^{2}$, com espaçamento de 0,40 m entre linhas, segundo recomendações de Carvalho (1999). Para o milheto, foi utilizada a variedade BN 2, semeada em linhas espaçadas de $0,17 \mathrm{~m}$, na dose de $20 \mathrm{~kg} \mathrm{ha}^{-1}$ de sementes, conforme recomendação de Salton \& Kichel (1998). O manejo da crotalária, do milheto e da vegetação espontânea - constituída predominantemente de capim colonião, trapoeraba, picão preto e corda-de-viola - foi mecânico, com triturador de palha, realizado em 30/11/2001 e 26/11/2002, no primeiro e segundo ano agrícola, respectivamente. Para essas plantas de cobertura, foi utilizada irrigação suplementar por aspersão, nos períodos de estiagem prolongada.

As semeaduras do milho foram realizadas, mecanicamente, em 5/12/2001 e 28/11/2002, utilizando-se o híbrido simples Pioneer 30F80, de ciclo semiprecoce, na densidade de 65 mil sementes por hectare, previamente tratadas com inseticida thiodicarb, na dose de $700 \mathrm{~g}$ de i.a. por $100 \mathrm{~kg}$ de sementes. A adubação de semeadura foi de $105 \mathrm{~kg} \mathrm{ha}^{-1}$ de $\mathrm{P}_{2} \mathrm{O}_{5}, 60 \mathrm{~kg} \mathrm{ha}^{-1}$ de $\mathrm{K}_{2} \mathrm{O}$ e $4 \mathrm{~kg} \mathrm{ha}^{-1}$ de $\mathrm{Zn}$, aplicada a $0,05 \mathrm{~m}$ abaixo e ao lado das sementes. No mesmo dia da semeadura do milho, foram aplicados os herbicidas glifosato e 2,4-D, nas doses (i.a.) de 1.080 e $670 \mathrm{~g} \mathrm{ha}^{-1}$, respectivamente. O controle de plantas daninhas em pós-emergência foi realizado com o milho no estádio de cinco folhas (V5), utilizando-se o herbicida Nicossulfuron, na dose de 60 g i.a. ha ${ }^{-1}$.

A marcação isotópica com ${ }^{15} \mathrm{~N}$ (uréia) foi utilizada nos tratamentos em que o milho recebeu a dose de $30 \mathrm{~kg} \mathrm{ha}^{-1}$ de $\mathrm{N}$, na semeadura, e naqueles tratamentos que receberam as doses de 50, 100 e $150 \mathrm{~kg} \mathrm{ha}^{-1}$ de $\mathrm{N}$ em cobertura, nos estádios quatro folhas ou oito folhas. Esses tratamentos tiveram microparcelas próprias de 1,0x2,4 m (três linhas de milho de 1,0x0,8 m), dentro da respectiva parcela. Em ambos os anos agrícolas, foram empregados um enriquecimento de $2 \%$ em átomos de ${ }^{15} \mathrm{~N}$ em excesso, para as doses $30 \mathrm{~kg}$ de $\mathrm{N}$ na semeadura e

Tabela 1. Resultados das análises químicas do solo, em amostras coletadas antes da instalação dos ensaios, nos meses de julho de 2001 e julho de 2002.

\begin{tabular}{|c|c|c|c|c|c|c|c|c|c|c|c|c|c|}
\hline $\begin{array}{c}\text { Camada } \\
\text { (m) }\end{array}$ & $\begin{array}{c}\mathrm{pH} \\
\mathrm{CaCl}_{2}\end{array}$ & $\begin{array}{l}\mathrm{N} \text { total } \\
\left(\mathrm{g} \mathrm{kg}^{-1}\right)\end{array}$ & $\begin{array}{c}\mathrm{MO} \\
\left(\mathrm{g} \mathrm{dm}^{-3}\right)\end{array}$ & $\begin{array}{c}\text { P resina } \\
\left(\mathrm{mg} \mathrm{dm}^{-3}\right)\end{array}$ & $\mathrm{Ca}$ & $\begin{array}{l}\mathrm{Mg} \\
--(\mathrm{mr}\end{array}$ & $\begin{array}{c}\mathrm{K} \\
\left.\mathrm{dm}^{-3}\right)\end{array}$ & Al+H & $\begin{array}{c}\mathrm{S} \\
\left(\mathrm{mg} \mathrm{dm}^{-3}\right)\end{array}$ & $\mathrm{Cu}$ & $\begin{array}{l}\mathrm{Fe} \\
--(\mathrm{m}\end{array}$ & $\underset{\left.g^{-1}\right)}{\mathrm{Mn}}$ & $\mathrm{Zn}$ \\
\hline & \multicolumn{13}{|c|}{$2001 / 2002$} \\
\hline $0,0-0,1$ & 5,1 & 0,9 & 21,1 & 11,9 & 17,7 & 15,7 & 2,3 & 22,1 & 6,5 & 2,5 & 16,1 & 20,2 & 0,4 \\
\hline $0,1-0,2$ & 4,8 & 0,8 & 19,2 & 6,0 & 11,5 & 7,4 & 1,0 & 23,5 & 6,0 & 2,5 & 16,7 & 16,2 & 0,3 \\
\hline $0,2-0,4$ & 4,6 & 0,5 & 11,8 & 2,8 & 7,8 & 6,6 & 0,7 & 19,6 & 7,3 & 1,5 & 8,3 & 4,5 & 0,1 \\
\hline \multicolumn{14}{|c|}{$2002 / 2003$} \\
\hline $0,0-0,1$ & 5,1 & 0,9 & 19,7 & 15,2 & 19,2 & 16,6 & 3,4 & 24,4 & 6,5 & 3,2 & 15,6 & 38,3 & 0,8 \\
\hline $0,1-0,2$ & 4,5 & 0,7 & 16,2 & 4,9 & 8,4 & 6,9 & 1,6 & 30,9 & 6,1 & 2,4 & 13,5 & 29,5 & 0,4 \\
\hline $0,2-0,4$ & 4,7 & 0,5 & 16,4 & 2,0 & 7,1 & 5,9 & 0,8 & 24,4 & 8,5 & 1,6 & 6,8 & 18,5 & 0,2 \\
\hline
\end{tabular}


$50 \mathrm{~kg} \mathrm{ha}^{-1}$ de $\mathrm{N}$ em cobertura e, de 1,5\% em átomos de ${ }^{15} \mathrm{~N}$ em excesso, para as doses 100 e $150 \mathrm{~kg} \mathrm{ha}^{-1}$ de $\mathrm{N}$ em cobertura. No restante da parcela, foi utilizada uréia comercial $45 \%$ de $\mathrm{N}$, sem enriquecimento em ${ }^{15} \mathrm{~N}$.

As coberturas nitrogenadas foram realizadas manualmente, em um sulco superficial, a 0,20 $\mathrm{m}$ da linha da cultura do milho e cobertas com uma camada de solo, para simular a aplicação mecanizada com implemento apropriado para cobertura nitrogenada incorporada ao milho em sistema plantio direto. No mesmo dia da aplicação de N, no estádio quatro folhas, em ambos os anos agrícolas, foram aplicados também $50 \mathrm{~kg} \mathrm{ha}^{-1}$ de $\mathrm{K}_{2} \mathrm{O}$, tendo como fonte o cloreto de potássio, conforme recomendação descrita em Raij et al. (1996).

A produtividade de matéria seca da parte aérea do milheto, da crotalária e da vegetação espontânea (pousio) foi determinada em quatro amostras, coletadas na área útil de cada parcela, um dia antes do manejo mecânico, e secadas em estufa de ventilação forçada de ar a $60^{\circ} \mathrm{C}$. Desse mesmo material, foram retiradas amostras para avaliar o teor de $\mathrm{N}$ total, conforme descrito em Malavolta et al. (1997), e avaliar a relação carbononitrogênio $(\mathrm{C} / \mathrm{N})$, que foi determinada pela combustão via seca da amostra a $1.400^{\circ} \mathrm{C}$, no aparelho Leco C/N .

$\mathrm{O}$ estande final foi determinado cinco dias antes da colheita, contando-se as plantas em quatro linhas de $2 \mathrm{~m}$, da área útil da parcela. O número de grãos por espiga foi avaliado em duas amostras de dez espigas, provenientes da área útil da parcela. A massa de mil grãos foi avaliada em duas amostragens, com a transformação dos dados para $13 \%$ de umidade.

Para a determinação da produtividade de matéria seca da parte aérea do milho, foram coletadas três plantas na área útil da parcela, por ocasião da maturação fisiológica. A produtividade de grãos foi determinada, tendo-se coletado as espigas das quatro linhas centrais da área útil da parcela, desprezando-se $1 \mathrm{~m}$ em cada extremidade. As espigas foram trilhadas mecanicamente, e os dados transformados em $\mathrm{kg} \mathrm{ha}^{-1}$ de grãos, padronizados a $13 \%$ de umidade.

Para análise do enriquecimento isotópico em porcentagem de átomos de ${ }^{15} \mathrm{~N}$ e $\mathrm{N}$ total, nos grãos e na parte aérea, foram coletadas três plantas na linha central das microparcelas, depois da maturação fisiológica dos grãos. As espigas foram debulhadas manualmente, e as folhas, colmos, pendões, sabugos e palhas da espiga, fragmentadas, retirando-se uma amostra para análises, as quais foram determinadas em espectrômetro de massa (IRMS), interfaceado com analisador elementar de $\mathrm{N}$, no Laboratório de Isótopos Estáveis do Cena/USP, conforme metodologia de Barrie \& Prosser (1996).
Os efeitos dos tratamentos foram avaliados pela produtividade de grãos $\left(\mathrm{kg} \mathrm{ha}^{-1}\right)$, produtividade de matéria seca da parte aérea $\left(\mathrm{kg} \mathrm{ha}^{-1}\right)$ e quantidade de $\mathrm{N}$ total acumulado pelo milho (grãos e parte aérea, $\mathrm{kg} \mathrm{ha}^{-1}$ ). Para a determinação da eficiência de utilização do $\mathrm{N}$, baseou-se no princípio da diluição isotópica, considerando-se o enriquecimento em porcentagem de átomos de ${ }^{15} \mathrm{~N}$ da fonte de $\mathrm{N}$ aplicada (uréia) e a quantidade de ${ }^{15} \mathrm{~N}$ na planta, descontando-se a variação natural do isótopo estável ${ }^{15} \mathrm{~N}$, que é de $0,366 \%$ (Barrie \& Prosser, 1996). Os cálculos para a determinação da recuperação do fertilizante nitrogenado foram feitos de acordo com Lara Cabezas et al. (2000).

Os dados foram submetidos à análise de variância, aplicando-se o teste $\mathrm{F}$, e a comparação de médias foi feita pelo teste de Tukey a 5\% de probabilidade e análise de regressão. As análises estatísticas foram realizadas, utilizando-se o SAS (SAS Institute, 1996).

\section{Resultados e Discussão}

A produtividade de matéria seca da parte aérea (Tabela 2) da crotalária foi superior à do milheto que, por sua vez, foi superior à da vegetação espontânea (pousio), em ambos os anos agrícolas. A crotalária apresentou também maior teor de $\mathrm{N}$ na matéria seca, o que é esperado, em razão de ser uma leguminosa, que pode adquirir $\mathrm{N}$ atmosférico pela fixação simbiótica (Ambrosano et al., 1997; Aita et al., 2001), além de reciclar $\mathrm{N}$ das camadas profundas do solo (Gonçalves et al., 2000). No entanto, alguns estudos com adubos verdes, marcados com ${ }^{15} \mathrm{~N}$, indicam que a maior proporção do $\mathrm{N}$ da biomassa dessas plantas tem, como destino, o solo (Harris \& Hesterman, 1990). Assim, o cultivo de adubos verdes pode favorecer outras culturas em rotação ou sucessão, graças ao efeito residual (Scivittaro et al., 2000)

Tabela 2. Produtividade de matéria seca da parte aérea das plantas de cobertura, teor de $\mathrm{N}$ total, quantidade de $\mathrm{N}$ acumulado e relação $\mathrm{C} / \mathrm{N}$, na época do manejo mecânico, nos anos de 2001 e de $2002^{(1)}$.

\begin{tabular}{lcccc}
\hline $\begin{array}{l}\text { Planta de } \\
\text { cobertura }\end{array}$ & $\begin{array}{c}\text { Matéria seca } \\
\left(\mathrm{kg} \mathrm{ha}^{-1}\right)\end{array}$ & $\begin{array}{c}\mathrm{N} \text { total } \\
\left(\mathrm{g} \mathrm{kg}^{-1}\right)\end{array}$ & $\begin{array}{c}\mathrm{N} \text { acumulado } \\
\left(\mathrm{kg} \mathrm{ha}^{-1}\right)\end{array}$ & $\begin{array}{c}\text { Relação } \\
\mathrm{C} / \mathrm{N}\end{array}$ \\
\hline \multicolumn{5}{c}{2001} \\
Crotalária & $9.770 \mathrm{a}$ & $17,30 \mathrm{a}$ & $169,0 \mathrm{a}$ & $21 \mathrm{c}$ \\
Milheto & $7.370 \mathrm{~b}$ & $9,30 \mathrm{c}$ & $68,5 \mathrm{~b}$ & $44 \mathrm{a}$ \\
$\mathrm{VE}^{(2)}$ & $2.490 \mathrm{c}$ & $11,28 \mathrm{~b}$ & $28,1 \mathrm{c}$ & $38 \mathrm{~b}$ \\
\hline \multicolumn{5}{c}{2002} \\
Crotalária & 8.610 & $21,95 \mathrm{a}$ & $189,0 \mathrm{a}$ & $20 \mathrm{c}$ \\
Milheto & $6.335 \mathrm{~b}$ & $10,10 \mathrm{c}$ & $64,0 \mathrm{~b}$ & $46 \mathrm{a}$ \\
VE & $2.860 \mathrm{c}$ & $11,85 \mathrm{~b}$ & $33,9 \mathrm{c}$ & $35 \mathrm{~b}$ \\
\hline
\end{tabular}

${ }^{(1)}$ Médias seguidas pela mesma letra, na coluna, não diferem entre si a $5 \%$ de probabilidade pelo teste de Tukey. ${ }^{(2)} \mathrm{VE}$ : vegetação espontânea. 
e, também, com o tempo, incrementar o teor de matéria orgânica do solo, o qual está diretamente relacionado com a adição de $\mathrm{N}$ ao solo, seja pela fixação biológica, seja por meio da adição de fertilizantes minerais ou orgânicos (Amado et al., 2002).

Apesar da menor produtividade de matéria seca do milheto, sua palhada promoveu uma cobertura mais persistente do solo, comparada à da crotalária e à da vegetação espontânea. Tal fato está relacionado à sua relação C/N (Salton \& Kichel, 1998), que foi maior que o dobro da relação $\mathrm{C} / \mathrm{N}$ da crotalária e superior à da vegetação espontânea. Na Região do Cerrado, especialmente, isto se constitui num importante fator no cultivo em plantio direto, em virtude de as altas temperaturas e umidade, no verão, promoverem uma rápida decomposição dos resíduos de baixa relação C/N (Gonçalves et al., 2000; Lara Cabezas et al., 2004).

A menor produção de matéria seca pela vegetação espontânea, quando comparada à dos adubos verdes, corrobora dados de Perin et al. (2004), que verificaram que a crotalária júncea produziu $31 \%$ a mais que o milheto e $108 \%$ a mais que a área de pousio. Entretanto, ressalta-se que a produtividade de matéria seca de plantas de coberturas do solo depende das condições intrínsecas de solo e clima local e, também, da época de cultivo, em virtude do fotoperíodo.

Durante os ciclos da cultura do milho, dezembro a abril dos anos agrícolas de 2001/2002 e 2002/2003, não houve incidência de períodos de estiagem (veranicos), comuns nessa região, que limitassem o desenvolvimento da cultura e influenciassem na produtividade de grãos.

O estande médio na colheita foi de aproximadamente 62 mil plantas por hectare, e não foi observada discrepância entre os tratamentos, o que indica que não houve interferência destes sobre a emergência e desenvolvimento das plantas. Isto ocorreu, provavelmente, em razão de a dose de $\mathrm{N}$, na semeadura, ter sido de $30 \mathrm{~kg} \mathrm{ha}^{-1}$ e de o $\mathrm{N}$ dos resíduos vegetais ter apresentado padrão de mineralização gradual, como da crotalária, que acumulou grande quantidade de N (Aita et al., 2001). A interferência do N, sobre a germinação de plântulas de milho, pode ocorrer, quando se aplica uma dose elevada de fertilizante mineral na semeadura, em virtude de sua salinidade reduzir o potencial hídrico do solo (Sá, 1996).

Verifica-se, na Tabela 3, que em ambos os anos agrícolas houve efeito significativo das doses de $\mathrm{N}$ e das plantas de cobertura do solo sobre o número de grãos por espiga, massa de mil grãos e produtividade de grãos. As épocas de aplicação do $\mathrm{N}$ influenciaram, significativamente, apenas na produtividade de grãos e somente no ano agrícola 2001/2002. Houve, também, para a pro- dutividade de grãos, interação significativa de doses de $\mathrm{N}$ com os sistemas de cobertura do solo, no primeiro ano agrícola, e de época de aplicação do $\mathrm{N}$ com os sistemas de cobertura do solo, no segundo ano (2002/2003). A interação entre diferentes variáveis, em anos distintos, apesar de terem sido utilizados os mesmos tratamentos, provavelmente ocorreu pelo fato de a dinâmica do $\mathrm{N}$ no solo e a cinética de decomposição dos resíduos vegetais serem dependentes das condições climáticas (Lara Cabezas et al., 2000; Amado et al., 2002).

O número de grãos por espiga e a massa de mil grãos foram superiores no milho cultivado em sucessão à crotalária, comparado ao cultivado em sucessão ao milheto e ao solo em pousio, que apresentaram comportamento semelhante entre si (Tabela 4). Esses componentes têm relação direta com a produtividade de grãos e alta dependência da absorção de $\mathrm{N}$ pelo milho (Schreiber et al., 1988; Ulger et al., 1995). Assim, certamente, condicionaram o milho a uma maior produtividade, cultivado em sucessão à crotalária, que apresentava maior potencial de fornecimento de $\mathrm{N}$, comparada ao dos demais sistemas de cobertura do solo (Tabela 2). As épocas de aplicação do $\mathrm{N}$ não influenciaram no número de grãos por espiga e na massa de mil grãos. Porém, em relação às doses de $\mathrm{N}$ aplicadas, esses componentes aumentaram de forma quadrática.

A menor produtividade de grãos de milho, em sucessão ao milheto (Tabela 4), comparada à do milho cultivado em sucessão à crotalária, provavelmente ocorreu em virtude da imobilização do $\mathrm{N}$ aplicado, pela microbiota do solo, para a decomposição dos resíduos e, também, pela maior imobilização do $\mathrm{N}$ do solo, que geralmente se constitui na principal fonte de $\mathrm{N}$ para as culturas (Coelho et al., 1991; Amado et al., 2002). Da mesma forma, pode ter ocorrido reimobilização do próprio

Tabela 3. Valores de F da análise de variância, referentes às avaliações de número de grãos por espiga, massa de mil grãos e produtividade de grãos, nos anos agrícolas 2001/2002 e 2002/2003.

\begin{tabular}{|c|c|c|c|c|c|c|}
\hline \multirow[t]{3}{*}{ Variável } & \multicolumn{2}{|c|}{$\begin{array}{l}\text { Grãos por } \\
\text { espiga }\end{array}$} & \multicolumn{2}{|c|}{$\begin{array}{l}\text { Massa de mil } \\
\text { grãos }(\mathrm{g})\end{array}$} & \multicolumn{2}{|c|}{$\begin{array}{l}\text { Produtividade de } \\
\text { grãos }\left(\mathrm{kg} \mathrm{ha}^{-1}\right)\end{array}$} \\
\hline & $2001 /$ & $2002 /$ & $2001 /$ & $2002 /$ & $2001 /$ & $2002 /$ \\
\hline & 2002 & 2003 & 2002 & 2003 & 2002 & 2003 \\
\hline Dose (D) & $6,01^{* *}$ & $26,70^{* *}$ & $11,85^{* *}$ & $51,15^{* *}$ & $141,35^{* *}$ & $180,62^{* *}$ \\
\hline Época (E) & $0,03^{\mathrm{ns}}$ & $3,12^{\mathrm{ns}}$ & $0,31^{\mathrm{ns}}$ & $1,01^{\mathrm{ns}}$ & $4,23^{*}$ & $30,08^{\text {ns }}$ \\
\hline Cobertura (C) & $6,60^{* *}$ & $10,22^{* *}$ & $33,03^{* *}$ & $25,35^{* *}$ & $166,60^{* *}$ & $106,15^{* *}$ \\
\hline DxE & $0,56^{\mathrm{ns}}$ & $0,23^{\text {ns }}$ & $0,78^{\mathrm{ns}}$ & $1,75^{\text {ns }}$ & $1,17^{\mathrm{ns}}$ & $0,33^{\mathrm{ns}}$ \\
\hline DxC & $1,54^{\mathrm{ns}}$ & $0,99^{\mathrm{ns}}$ & $1,67^{\mathrm{ns}}$ & $1,98^{\mathrm{ns}}$ & $4,57^{* *}$ & $0,35^{\text {ns }}$ \\
\hline ExC & $0,11^{\mathrm{ns}}$ & $1,14^{\mathrm{ns}}$ & $1,28^{\mathrm{ns}}$ & $0,96^{\mathrm{ns}}$ & $2,50^{\mathrm{ns}}$ & $3,66^{*}$ \\
\hline DxExC & $0,17^{\text {ns }}$ & $0,37^{\text {ns }}$ & $0,73^{\text {ns }}$ & $0,74^{\mathrm{ns}}$ & $1,37^{\mathrm{ns}}$ & $0,37^{\mathrm{ns}}$ \\
\hline
\end{tabular}


$\mathrm{N}$ mineralizado do milheto. Assim, todos esses fatores, possivelmente, condicionaram um assincronismo entre a época de demanda de $\mathrm{N}$ pela planta e a disponibilidade de $\mathrm{N}$ na solução do solo. Grande parte do $\mathrm{N}$ mineralizado dos resíduos vegetais pode ter sido incorporado ao N orgânico do solo, corroborando o verificado por Harris \& Hesterman (1990).

A aplicação do N no estádio quatro folhas (Tabela 4) proporcionou maior produtividade de grãos no primeiro ano agrícola, certamente pela compensação do $\mathrm{N}$ mineral da solução do solo imobilizado, na fase inicial de desenvolvimento do milho, em relação aos tratamentos que receberam o $\mathrm{N}$ no estádio oito folhas. No SPD, pesquisas têm demonstrado que a maior presença de resíduos orgânicos, na superfície do solo, favorece uma maior atividade e imobilização do $\mathrm{N}$ pelos microrganismos quimiorganotróficos (Sá, 1996; Aita et al., 2001), o que pode comprometer a disponibilidade de $\mathrm{N}$ para o milho (Amado et al., 2002; Bortolini et al., 2002). Além disso, a produção potencial da cultura do milho, ou seja, os componentes de produção como número de fileiras de grãos por espiga e tamanho da espiga são definidos nos estádios de quatro a seis folhas e necessitam, nessa época, de um suprimento adequado de $\mathrm{N}$, conforme relatado por Mengel \& Barber (1974). Nessa fase, a deficiência de $\mathrm{N}$ reduz o número de óvulos nos primórdios da espiga (Schreiber et al., 1988).

No desdobramento da interação significativa de épocas de aplicação do $\mathrm{N}$ com os sistemas de cobertura do solo, para a produtividade de grãos, ano agrícola 2002/2003, a maior resposta foi para a sucessão crotalária-milho (7.756 kg ha-1), em relação à sucessão

Tabela 4. Número de grãos por espiga, massa de mil grãos (g) e produtividade de grãos $\left(\mathrm{kg} \mathrm{ha}^{-1}\right)$, em função das variáveis época de aplicação do $\mathrm{N}$ e sistema de cobertura do solo, nos anos agrícolas 2001/2002 e 2002/2003(1).

\begin{tabular}{|c|c|c|c|c|c|c|}
\hline \multirow[t]{2}{*}{ Variável } & \multicolumn{2}{|c|}{$\begin{array}{c}\text { Grãos } \\
\text { por espiga }\end{array}$} & \multicolumn{2}{|c|}{$\begin{array}{l}\text { Massa de } \\
\text { mil grãos }\end{array}$} & \multicolumn{2}{|c|}{$\begin{array}{l}\text { Produtividade } \\
\text { de grãos }\end{array}$} \\
\hline & $\begin{array}{l}2001 / \\
2002\end{array}$ & $\begin{array}{l}2002 / \\
2003\end{array}$ & $\begin{array}{l}2001 / \\
2002 \\
\end{array}$ & $\begin{array}{l}2002 / \\
2003\end{array}$ & $\begin{array}{l}2001 / \\
2002 \\
\end{array}$ & $\begin{array}{l}2002 / \\
2003\end{array}$ \\
\hline \multicolumn{7}{|l|}{ Sistema de cobertura } \\
\hline Crotalária-milho & $513,3 \mathrm{a}$ & $512,9 \mathrm{a}$ & $290,4 a$ & $304,3 \mathrm{a}$ & 7.790 & 7.755 \\
\hline Pousio-milho & $494,2 b$ & $491,2 b$ & $269,3 b$ & $290,1 b$ & 6.339 & 6.345 \\
\hline Milheto-milho & $469,5 \mathrm{~b}$ & $475,6 \mathrm{~b}$ & $268,7 \mathrm{~b}$ & $289,5 \mathrm{~b}$ & 5.862 & 6.068 \\
\hline \multicolumn{7}{|c|}{ Época de aplicação do $\mathrm{N}$} \\
\hline Quatro folhas & $497,0 \mathrm{a}$ & $499,2 \mathrm{a}$ & $276,8 \mathrm{a}$ & $293,0 \mathrm{a}$ & $6.756 a$ & 6.810 \\
\hline Oito folhas & $486,3 \mathrm{a}$ & $487,3 \mathrm{a}$ & $275,4 a$ & $296,0 \mathrm{a}$ & $6.571 \mathrm{~b}$ & 6.632 \\
\hline
\end{tabular}

(1) Médias seguidas pela mesma letra, na coluna, não diferem entre si a $5 \%$ de probabilidade pelo teste de Tukey. (2)Médias sem letra, na coluna, referem-se à interação significativa de sistema de cobertura do solo $\mathrm{x}$ doses de $\mathrm{N}$ e de sistemas de cobertura x épocas de aplicação do $\mathrm{N}$. pousio-milho (6.341 kg ha-1), e a aplicação do N, no estádio quatro ou oito folhas, não influenciou significativamente nessas sucessões. A produtividade de grãos, na sucessão milheto-milho, $6.338 \mathrm{~kg} \mathrm{ha}^{-1}$ e $5.798 \mathrm{~kg} \mathrm{ha}^{-1}$, para a aplicação do $\mathrm{N}$ nos estádios quatro e oito folhas, respectivamente, foi inferior à da sucessão pousio-milho somente quando o $\mathrm{N}$ foi aplicado no estádio oito folhas.

A maior resposta em produtividade de grãos para o milho cultivado, em sucessão à crotalária, e a não-diferença quanto às épocas de aplicação do $\mathrm{N}$ seguramente ocorreram em razão do maior e mais regular fornecimento de $\mathrm{N}$ por esta leguminosa, em virtude de sua menor $\mathrm{C} / \mathrm{N}$ favorecer a maior mineralização e menor imobilização de $\mathrm{N}$ mineral, comparado aos resíduos do milheto e da vegetação espontânea. Ademais, o maior aporte de $\mathrm{N}$ pela crotalária pode ter favorecido um desenvolvimento maior do sistema radicular, tendo resultado em um maior aproveitamento de água e nutrientes do solo (Jenkinson et al., 1985) e em maior mineralização do N orgânico do solo (Rao et al., 1992).

A produtividade de grãos, no ano agrícola 2001/2002, aumentou de forma quadrática em função das doses de $\mathrm{N}$ aplicadas, e a máxima eficiência técnica foi alcançada com as doses 144, 149 e $161 \mathrm{~kg} \mathrm{ha}^{-1}$ de N, para o milho cultivado em sucessão à crotalária, pousio e milheto, respectivamente (Figura 1). Embora o milho em sucessão ao milheto tenha sido o sistema que demandou a maior dose de $\mathrm{N}$ para atingir a máxima eficiência técnica, foi o sistema que proporcionou a menor produtividade de grãos, ao contrário da crotalária, que proporcionou maior produtividade com uma menor dose de N. No segundo ano agrícola, não houve interação entre os tratamentos, e a máxima produtividade de grãos foi alcançada com $174 \mathrm{~kg} \mathrm{ha}^{-1}$ de $\mathrm{N}$.

As porcentagens de $\mathrm{N}$ na planta proveniente do fertilizante (\%NPPF) foram semelhantes nos grãos e no restante da parte aérea da planta - em média, 23\% -, o que decorre da alta mobilidade do $\mathrm{N}$ e da dinâmica dos compostos nitrogenados (Coelho et al., 1991; Ta \& Weiland, 1992). Entretanto, verifica-se que a maior parte do N na planta, $77 \%$, foi proveniente do solo e outras fontes (resíduos vegetais das plantas de cobertura, precipitação pluvial, fixação biológica), corroborando o observado por Lara Cabezas et al. (2000), também em Latossolo Vermelho de Cerrado, sob plantio direto. Esses dados demonstram a importância do $\mathrm{N}$ orgânico do solo e do $\mathrm{N}$ proveniente de outras fontes como adubos verdes, no fornecimento de $\mathrm{N}$ para o milho. 
De-Polli \& Chada (1989) verificaram que a adubação verde, incorporada ou em cobertura, em solo de baixo potencial produtivo, proporcionou rendimento de grãos de milho maior do que com a aplicação de $\mathrm{N}$ mineral, e até quatro vezes superior ao tratamento sem a aplicação de $\mathrm{N}$.

A quantidade total de $\mathrm{N}$ na planta de milho (parte aérea + grãos) proveniente do fertilizante (QNPPF), em ambos os anos agrícolas, aumentou com o incremento da dose de $\mathrm{N}$ aplicada nos três sistemas de cobertura do solo (Figura 2), e os dados ajustaramse a um modelo quadrático. A maior QNPPF (parte aérea+grãos), no primeiro ano agrícola, foi observada no milho cultivado em sucessão à crotalária e ao solo em pousio, e menor no milho em sucessão ao milheto (Tabela 5). No segundo ano agrícola, a maior QNPPF ocorreu no milho cultivado em sucessão à crotalária, não tendo havido diferença no cultivo em sucessão ao pousio e ao milheto. A mesma tendência, quanto às sucessões de culturas e as épocas de aplicação do N, foi
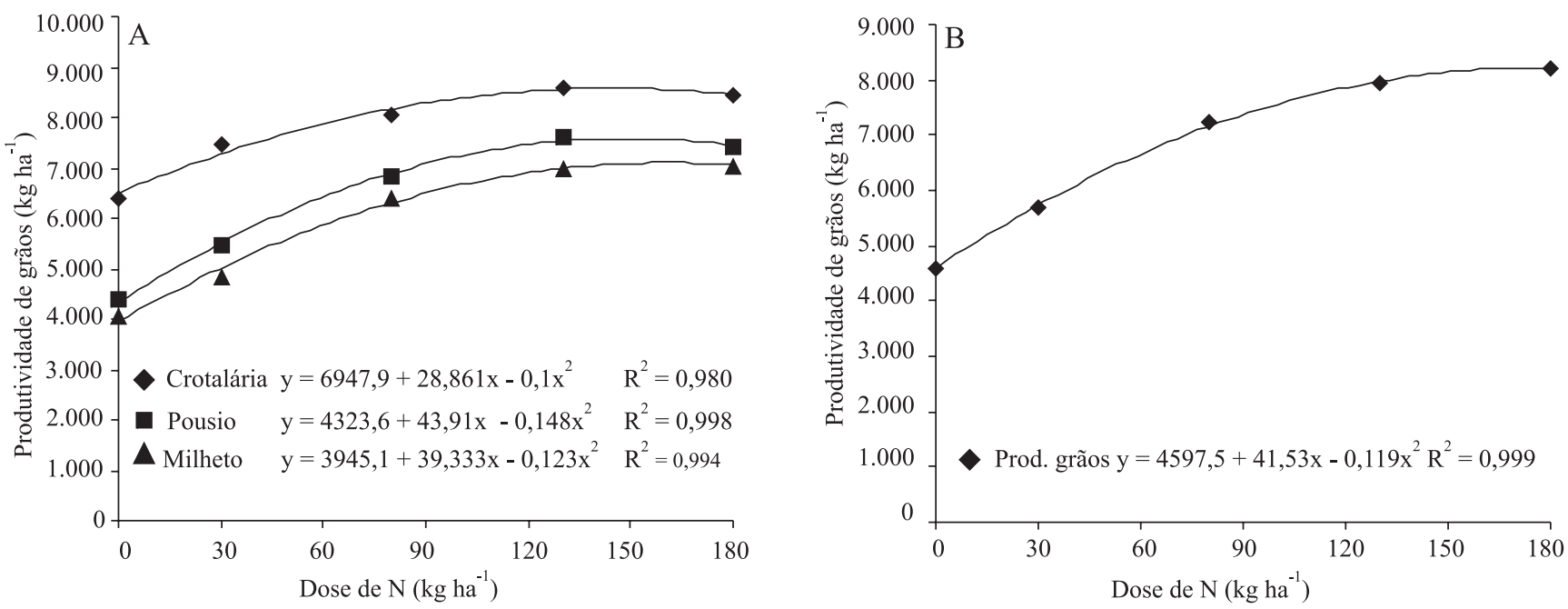

Figura 1. Desdobramento da interação significativa entre doses de N e sistemas de cobertura do solo, para produtividade de grãos de milho, no ano agrícola 2001/2002 (A), e produtividade média de grãos em função de doses de N, no ano agrícola 2002/ 2003(B).
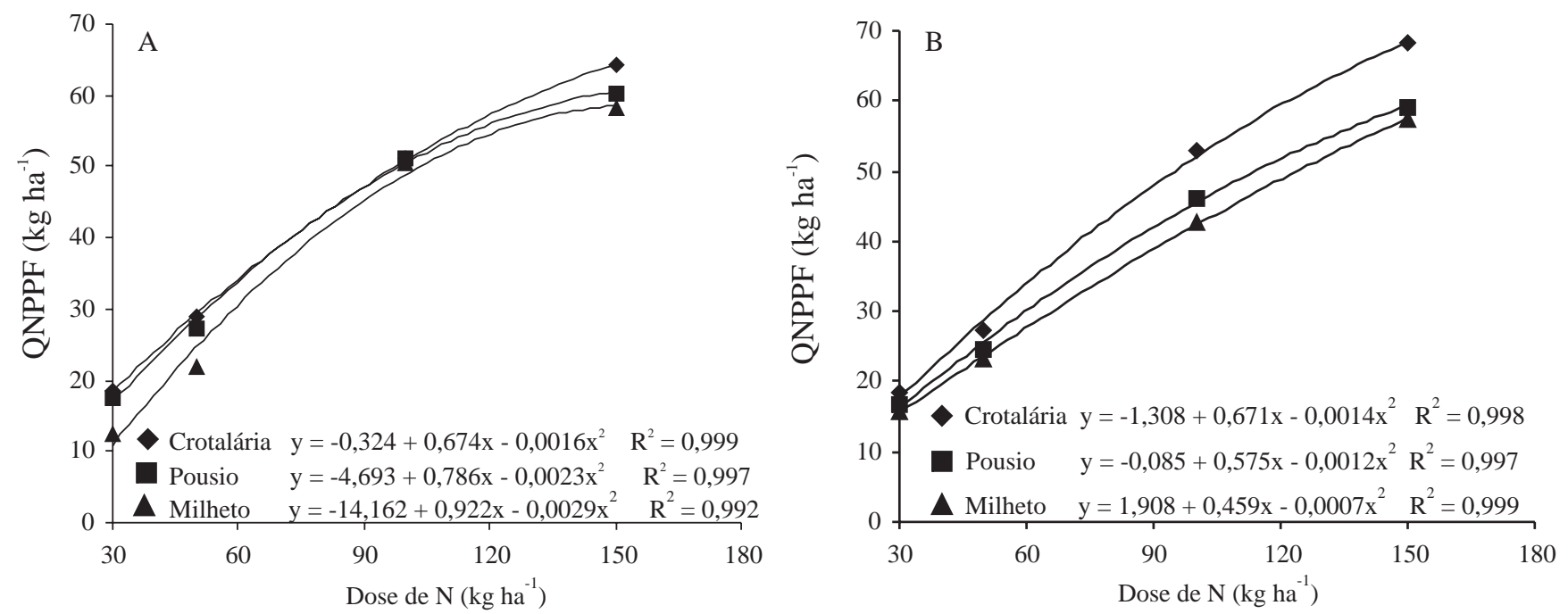

Figura 2. Quantidade de nitrogênio proveniente do fertilizante (QNPPF), na planta de milho (parte aérea + grãos), em função de doses de $\mathrm{N}$ aplicadas nos estádios quatro e oito folhas, e de sistemas de cobertura do solo, nos anos agrícolas 2001/2002 (A) e 2002/2003(B). 
também observada para o aproveitamento do $\mathrm{N}$ proveniente do fertilizante pelo milho.

A menor relação $\mathrm{C} / \mathrm{N}$ da crotalária promoveu, provavelmente, uma menor imobilização do $\mathrm{N}$ do fertilizante pelos microrganismos quimiorganotróficos do solo. Além disso, deve-se considerar a maior produtividade de biomassa do milho, cultivado em sucessão a essa leguminosa, conseqüentemente acumulando mais $\mathrm{N}$. A maior produtividade de grãos de milho e aproveitamento do $\mathrm{N}$, em sucessão à crotalária, indicam que as condições intrínsecas do solo foram mais favoráveis à absorção de $\mathrm{N}$ pela planta, provavelmente em razão de maior desenvolvimento radicular (Scivittaro et al., 2000), e também da maior oferta de outros nutrientes que, certamente, foram mineralizados junto com o $\mathrm{N}$.

Embora as épocas de aplicação do $\mathrm{N}$ tenham influenciado na produtividade de grãos (Tabela 4), principalmente no milho cultivado em sucessão ao milheto, estas não influenciaram na QNPPF e no aproveitamento do N do fertilizante, pelo milho (Tabela 5). Deste modo, possivelmente, a maior resposta em produtividade de grãos de milho, com a aplicação do N no estádio quatro folhas (primeiro ano agrícola e sucessão milheto-milho, no segundo), deve-se ao fato de o $\mathrm{N}$ do fertilizante ter promovido, indiretamente, maior aproveitamento do $\mathrm{N}$ do

Tabela 5. Quantidade de nitrogênio na planta proveniente do fertilizante (QNPPF) e aproveitamento de nitrogênio, aplicado nos estádios quatro e oito folhas no milho, em sucessão à crotalária, milheto e pousio, nos anos agrícolas 2001/2002 e 2002/2003(1)

\begin{tabular}{|c|c|c|c|c|c|c|}
\hline \multirow[t]{2}{*}{ Variável } & \multicolumn{3}{|c|}{ QNPPF } & \multicolumn{3}{|c|}{ Aproveitamento do $\mathrm{N}$} \\
\hline & Grãos & $\begin{array}{l}\text { Parte } \\
\text { aérea } \\
\left.\mathrm{g} \mathrm{ha}^{-1}\right)\end{array}$ & Total & Grãos & $\begin{array}{l}\text { Parte } \\
\text { aérea } \\
(\%)--\end{array}$ & Total \\
\hline & \multicolumn{6}{|c|}{$2001 / 2002$} \\
\hline \multicolumn{7}{|l|}{ Sistema de cobertura } \\
\hline Crotalária-milho & $26,1 \mathrm{a}$ & $15,3 \mathrm{a}$ & $41,4 \mathrm{a}$ & $33,4 a$ & $20,6 a$ & $54,0 \mathrm{a}$ \\
\hline Pousio-milho & $25,1 \mathrm{ab}$ & $14,5 \mathrm{a}$ & $39,6 a$ & $32,4 a$ & $19,0 \mathrm{a}$ & $51,4 a$ \\
\hline Milheto-milho & $23,6 b$ & $12,2 b$ & $35,8 b$ & $28,0 \mathrm{~b}$ & $15,7 b$ & $43,7 b$ \\
\hline \multicolumn{7}{|c|}{ Época de aplicação do $\mathrm{N}$} \\
\hline Quatro folhas & $25,3 \mathrm{a}$ & $14,5 \mathrm{a}$ & $39,8 \mathrm{a}$ & $31,0 \mathrm{a}$ & $18,8 \mathrm{a}$ & $49,8 \mathrm{a}$ \\
\hline Oito folhas & $24,5 b$ & $13,5 b$ & $38,0 \mathrm{a}$ & $31,6 \mathrm{a}$ & $18,1 \mathrm{a}$ & $49,7 \mathrm{a}$ \\
\hline \multicolumn{7}{|c|}{$2001 / 2002$} \\
\hline \multicolumn{7}{|l|}{ Sistema de cobertura } \\
\hline Crotalária-milho & $27,5 \mathrm{a}$ & $14,1 \mathrm{a}$ & $41,6 \mathrm{a}$ & $34,4 \mathrm{a}$ & $19,0 \mathrm{a}$ & $53,4 \mathrm{a}$ \\
\hline Pousio-milho & $23,5 b$ & $13,1 \mathrm{ab}$ & $36,6 b$ & $30,5 b$ & $17,1 \mathrm{a}$ & $47,6 \mathrm{~b}$ \\
\hline Milheto-milho & $22,8 b$ & $12,0 \mathrm{~b}$ & $34,8 \mathrm{~b}$ & $29,3 b$ & $16,5 \mathrm{a}$ & $45,8 b$ \\
\hline \multicolumn{7}{|c|}{ Época de aplicação do N } \\
\hline Quatro folhas & $25,3 a$ & $13,5 \mathrm{a}$ & $38,8 \mathrm{a}$ & $30,8 \mathrm{a}$ & $17,4 \mathrm{a}$ & $48,2 \mathrm{a}$ \\
\hline Oito folhas & $23,9 \mathrm{a}$ & $12,6 \mathrm{a}$ & $36,5 \mathrm{a}$ & $32,1 \mathrm{a}$ & $17,6 \mathrm{a}$ & $49,7 \mathrm{a}$ \\
\hline
\end{tabular}

(1)Médias seguidas pela mesma letra, na coluna, não diferem entre si a 5\% de probabilidade pelo teste de Tukey. solo pelo milho, por meio da mineralização dos resíduos das plantas de cobertura ou do N orgânico do solo. Além disso, pode ter favorecido o maior desenvolvimento do sistema radicular (Jenkinson et al., 1985), condicionando também maior aproveitamento do $\mathrm{N}$ do solo, que, na maioria das vezes, é a principal fonte de $\mathrm{N}$ para as culturas (Rao et al., 1992).

$\mathrm{O}$ aproveitamento relativo do $\mathrm{N}$ do fertilizante, em ambos os anos agrícolas, decresceu com o incremento das doses de $\mathrm{N}$ aplicadas, nos três sistemas de cobertura do solo estudados, exceto para a sucessão milhetomilho, no primeiro ano agrícola, em que o aproveitamento foi um pouco menor nas doses de 30 e $50 \mathrm{~kg} \mathrm{ha}^{-1}$ de $\mathrm{N}$, em relação à dose de $100 \mathrm{~kg} \mathrm{ha}^{-1}$ de $\mathrm{N}$ (Figura 3). Isto ocorreu, provavelmente, em conseqüência do processo de imobilização microbiana do $\mathrm{N}$ e da alta relação $\mathrm{C} / \mathrm{N}$ dessa gramínea, porém foi também menor na dose de $150 \mathrm{~kg} \mathrm{ha}^{-1}$ de N. Comportamentos semelhantes foram observados por Timmons \& Baker (1992), com ${ }^{15} \mathrm{~N}$, em plantio direto e, também, em plantio convencional (Coelho et al., 1991). No entanto, ressalta-se que a recuperação é relativa à dose de $\mathrm{N}$ aplicada e, assim como observado neste estudo, a quantidade de $\mathrm{N}$ absorvido pelo milho normalmente aumenta com o incremento da dose de $\mathrm{N}$ aplicada.

Verifica-se que, em ambas as épocas de aplicação do $\mathrm{N}$, em média, o aproveitamento do $\mathrm{N}$ foi inferior a 50\% do aplicado como fertilizante (Tabela 5). Existe uma grande variação no aproveitamento do $\mathrm{N}$ do fertilizante pelo milho, que raramente ultrapassa $50 \%$ do $\mathrm{N}$ aplicado (Scivittaro et al., 2000). Essas diferenças ocorrem em virtude de diversos fatores, principalmente das condições edafoclimáticas, o tipo de fertilizante e o sistema de cultivo (Lara Cabezas et al., 2000; Figueiredo et al., 2005).

A distribuição do $\mathrm{N}$ acumulado na parte aérea do milho foi semelhante em todos os tratamentos. Em média, $64 \%$ do $\mathrm{N}$ alocou-se nos grãos e $36 \%$ no restante da parte aérea do milho, evidenciando que o maior dreno de $\mathrm{N}$ na planta são os grãos, e que grande quantidade de $\mathrm{N}$ das partes vegetativas foi translocado para eles, passando a fazer parte de aminoácidos e proteínas (Ta \& Weiland, 1992). Distribuição semelhante a essa, entre o grão e o restante da parte aérea da planta, também foi observada em outros trabalhos, tanto em plantio direto como convencional, demonstrando a mesma partição de N (Timmons \& Cruse, 1990; Timmons \& Baker, 1992; Lara Cabezas et al., 2000).

Verifica-se que grande parte do $\mathrm{N}$ do fertilizante (36\%) absorvido pela planta retornou ao solo, pelos 

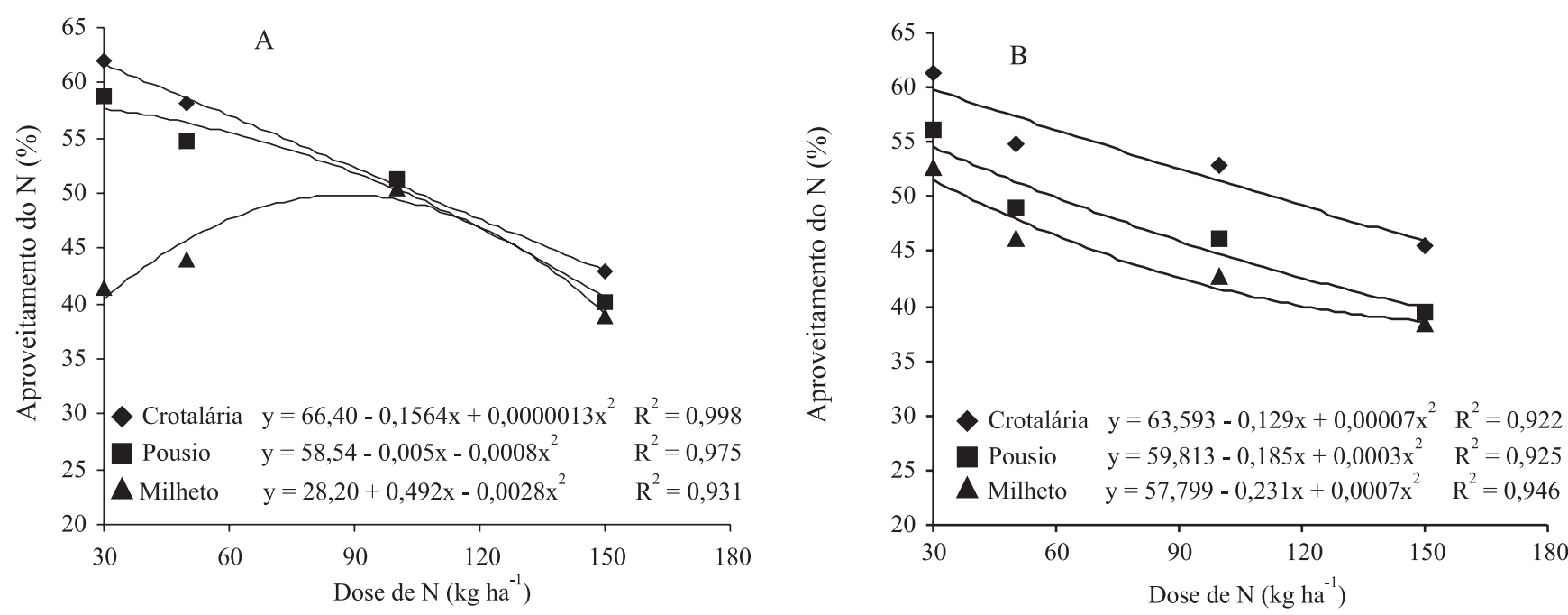

Figura 3. Aproveitamento do $\mathrm{N}$ do fertilizante pelo milho, em função de doses de $\mathrm{N}$, aplicadas nos estádios quatro e oito folhas, e de sistemas de cobertura do solo, nos anos agrícolas 2001/2002 (A) 2003/2003 (B).

resíduos culturais, e que parte foi remineralizada e parte interagiu com a matéria orgânica mais estável do solo, o que é governado pela qualidade do resíduo, principalmente pela relação $\mathrm{C} / \mathrm{N}$, lignina/N e polifenóis/N (Amado et al., 2002). Ressalta-se, ainda, que a porção de $\mathrm{N}$ que retorna ao solo deve ser superior à observada, por não estar sendo considerado o $\mathrm{N}$ do sistema radicular.

\section{Conclusões}

1. O incremento na dose de $\mathrm{N}$ proporciona aumento quadrático na quantidade, na planta, de $\mathrm{N}$ proveniente do fertilizante e na produtividade de grãos.

2. O cultivo do milho, em sucessão à crotalária, proporciona maior produtividade de grãos, quantidade de $\mathrm{N}$ na planta proveniente do fertilizante, absorção e recuperação do $\mathrm{N}$ em relação ao pousio e ao milheto.

3. As épocas de aplicação do $\mathrm{N}$ não influenciam na quantidade de $\mathrm{N}$ proveniente do fertilizante, na planta, nem na recuperação do $\mathrm{N}$ do fertilizante.

4. A aplicação do $\mathrm{N}$ no estádio quatro folhas proporciona maior produtividade de grãos de milho, em sucessão ao milheto, comparada à aplicação com oito folhas.

\section{Agradecimentos}

À Fapesp, pela concessão de bolsa; à International Atomic Energy Agency - IAEA, pelo fornecimento do ${ }^{15} \mathrm{~N}$; à Unesp/Feis, pela autorização de uso do espaço físico, máquinas e implementos.

\section{Referências}

AITA, C.; BASSO, C.J.; CERETTA, C.A.; GONÇALVES, C.N.; DA ROS, C.O. Plantas de cobertura do solo como fonte de nitrogênio ao milho. Revista Brasileira de Ciência do Solo, v.25, p.157-165, 2001.

AMADO, T.J.C.; MIELNICZUK, J.; AITA, C. Recomendação de adubação nitrogenada para o milho no RS e SC adaptada ao uso de culturas de cobertura do solo, sob plantio direto. Revista Brasileira de Ciência do Solo, v.26, p.241-248, 2002.

AMBROSANO, E.J.; TRIVELIN, P.C.O.; MURAOKA, T. Técnica para marcação dos adubos verdes crotalária júncea e mucuna-preta com ${ }^{15} \mathrm{~N}$ para estudos de dinâmica do nitrogênio. Bragantia, v.56, p.219-224, 1997.

BARRIE, A.; PROSSER, S.J. Automated analysis of light-element stable isotopes by isotope ratio mass spectrometry. In: BOUTTON, T.W.; YAMASAKI, S. (Ed.). Mass spectrometry of soils. New York: M. Dekker, 1996. p.1-46.

BORTOLINI, C.G.; SILVA, P.R.F. da; ARGENTA, G.; FORSTHOFER, E.L. Sistemas de aplicação de nitrogênio e seus efeitos sobre o acúmulo de N na planta de milho. Revista Brasileira de Ciência do Solo, v.26, p.361-366, 2002.

CARVALHO, A.M. Alternativas para plantio direto e adubação verde na região do Cerrado. Planaltina: Embrapa Cerrados, 1999. 2p. (Guia Técnico do Produtor Rural, 23).

COELHO, A.M.; FRANÇA, G.E.; BAHIA FILHO, A.F.C.; GUEDES, G.A.A. Balanço de nitrogênio ${ }^{15} \mathrm{~N}$ em um Latossolo Vermelho-escuro, sob vegetação de cerrado, cultivado com milho. Revista Brasileira de Ciência do Solo, v.15, p.187-193, 1991.

CONAB. Série histórica da área plantada por produtos 1990/91 a 2003/04. Disponível em: <http://www.conab.gov.br>. Acesso em:10 jan. 2005. 
DE-POLLI, H.; CHADA, S. de S. Adubação verde incorporada ou em cobertura na produção de milho em solo de baixo potencial de produtividade. Revista Brasileira de Ciência do Solo, v.13, p.287293, 1989

EMBRAPA. Centro Nacional de Pesquisa de Solos (Rio de Janeiro, RJ). Sistema brasileiro de classificação de solos. Rio de Janeiro: Embrapa-CNPS; Brasília: Embrapa-SCT, 1999. 412p.

FIGUEIREDO, C.C. de; RESCK, D.V.S.; GOMES, A.C.; URQUIAGA, S. Sistemas de manejo na absorção de nitrogênio pelo milho em um Latossolo Vermelho no Cerrado. Pesquisa Agropecuária Brasileira, v.40, p.279-287, 2005.

GONÇALVES, C.N.; CERETTA, C.A.; BASSO, C.J. Sucessões de culturas com plantas de cobertura e milho em plantio direto e sua influência sobre o nitrogênio do solo. Revista Brasileira de Ciência do Solo, v.24, p.153-159, 2000.

HARRIS, G.H.; HESTERMAN, O.B. Quantifying the nitrogen contribution from alfalfa to soil and two succeeding crops using nitrogen-15. Agronomy Journal, v.82, p.129-134, 1990.

JENKINSON, D.S.; FOX, R.H.; RAYNER, J.H. Interactions between fertilizer nitrogen and soil nitrogen - the so-called "priming effect”. Journal of Soil Science, v.36, p.425-444, 1985.

LARA CABEZAS, W.A.R.; ALVES. B.J.R.; URQUIAGA, S.; SANTANA, D.G. de. Influência da cultura antecessora e da adubação nitrogenada na produtividade de milho em sistema plantio direto e solo preparado. Ciência Rural, v.34, p.1005-1013, 2004.

LARA CABEZAS, W.A.R.; TRIVELIN, P.C.O.; KORNDÖRFER, G.H.; PEREIRA, S. Balanço da adubação nitrogenada sólida e fluida de cobertura na cultura do milho em sistema plantio direto no Triângulo Mineiro (MG). Revista Brasileira de Ciência do Solo, v.24, p.363-376, 2000.

MALAVOLTA, E.; VITTI, G.C.; OLIVEIRA, S.A. Avaliação do estado nutricional das plantas: princípios e aplicações. 2.ed. Piracicaba: Potafos, 1997. 319p.

MENGEL, D.B.; BARBER, S.A. Rate of nutrient uptake per unit of corn root under field conditions. Agronomy Journal, v.66, p.399402, 1974.

PERIN, A.; SANTOS, R.H.S.; URQUIAGA, S.; GUERRA, J.G.M.; CECON, P.R. Produção de fitomassa, acúmulo de nutrientes e fixação biológica de nitrogênio por adubos verdes em cultivo isolado e consorciado. Pesquisa Agropecuária Brasileira, v.39, p.35-40, 2004.

RAIJ, B. van; ANDRADE, J.C. de; CANTARELLA, H.; QUAGGIO, J.A. Análise química para avaliação da fertilidade de solos tropicais. Campinas: Instituto Agronômico, 2001. 285p.

RAIJ, B. van; CANTARELLA, H.; QUAGGIO, J.A.; FURLANI, A.M.C. Recomendações de adubação e calagem para o Estado de São Paulo. 2.ed. Campinas: Instituto Agronômico, 1996. 285p. (Boletim técnico, 100).

RAO, A.C.S.; SMITH, J.L.; PARR, J.F.; PAPENDICK, R.I. Considerations in estimating nitrogen recovery efficiency by the difference and isotopic dilution methods. Fertilizer Research, v.33, p.209-217, 1992.

SÁ, J.C.M. Manejo de nitrogênio na cultura de milho no sistema plantio direto. Passo Fundo: Aldeia Norte, 1996. 23p.

SALTON, J.C.; KICHEL, A.N. Milheto: uma alternativa para cobertura do solo e alimentação animal. Revista Plantio Direto, v.45, p.41-43, 1998.

SAS INSTITUTE (Cary, Estados Unidos). The SAS-system for Windows release 6.11 (software). Cary, 1996. 1 CD-ROM.

SCHREIBER, H.A.; STANBERRY, C.O.; TUCKER, H. Irrigation and nitrogen effects on sweet corn row numbers at various growth stages. Science, v.135, p.135-136, 1988.

SCIVITTARO, W.B.; MURAOKA, T.; BOARETTO, A.E.; TRIVELIN, P.C.O. Utilização de nitrogênio de adubos verde e mineral pelo milho. Revista Brasileira de Ciência do Solo, v.24, p.917926, 2000.

TA, C.T.; WEILAND, R.T. Nitrogen partitioning in maize during ear development. Crop Science, v.32, p.443-451, 1992.

TIMMONS, D.R.; BAKER, J.L. Fertilizer management effect on recovery of labeled nitrogen by continuous no-till. Agronomy Journal, v.84, p.490-496, 1992.

TIMMONS, D.R.; CRUSE, R.M. Effect of fertilization method and tillage on nitrogen-15 recovery by corn. Agronomy Journal, v.82, p.777-784, 1990.

ULGER, A.C.; BECKER, A.C.; KHANT, G. Response of maize inbred lines and hybrids to increasing rates of nitrogen fertilizer. Journal of Agronomy and Crop Science, v.159, p.157-163, 1987. 